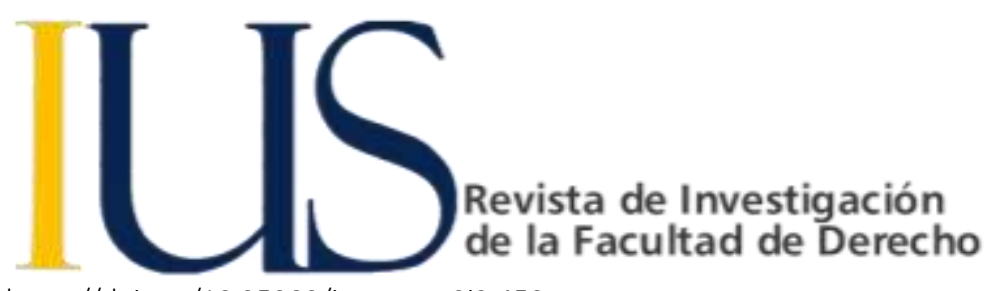

\title{
Hacia una adecuada regulación del derecho a la desconexión digital en el Perú y la actuación de la inspección del trabajo
}

\author{
Melissa Távara Romero ${ }^{1}$, Guillermo Enrique Chira Rivero ${ }^{2}$
}

\begin{tabular}{|c|c|}
\hline INFORMACIÓN DEL ARTÍCULO & RESUMEN \\
\hline \multicolumn{2}{|l|}{ Historia del artículo: } \\
\hline $\begin{array}{l}\text { Recibido el } 25 \text { de noviembre de } \\
2020\end{array}$ & \multirow{9}{*}{$\begin{array}{l}\text { Una nueva "laboralidad tecnológica" ha irrumpido nuestras vidas, la } \\
\text { declaración del estado de emergencia terminó por evidenciar que nuestra } \\
\text { normativa laboral no estaba "preparada" para afrontar los problemas laborales } \\
\text { suscitados a raíz de la pandemia. Sin embargo, el Estado peruano, a través de } \\
\text { diversos decretos de urgencia (DU) trató de paliar los escenarios ocasionados } \\
\text { ante la imposibilidad de la realización de trabajo presencial. Es así que, } \\
\text { mediante el DU 026-2020 de fecha } 15 \text { de marzo de } 2020 \text { se instauró el trabajo } \\
\text { remoto; posteriormente, el } 01 \text { de noviembre de } 2020 \text {, el DU } 127-2020 \text {, trajo } \\
\text { consigo el reconocimiento del derecho a la desconexión digital; no obstante, al } \\
\text { ser una medida de carácter excepcional y temporal, su regulación a través de } \\
\text { un DU, no es suficiente. Por ello, la presente investigación pretende brindar un } \\
\text { alcance para su adecuada regulación, la cual debe ir de la mano con la } \\
\text { actuación de la inspección del trabajo. }\end{array}$} \\
\hline Aceptado el 29 de diciembre de & \\
\hline 2020 & \\
\hline Palabras claves: & \\
\hline Derecho a la desconexión digital & \\
\hline Decreto de urgencia & \\
\hline Protección de derechos & \\
\hline fundamentale & \\
\hline & \\
\hline
\end{tabular}

Towards a regulation of the right to digital disconnection in Peru and the role of the labor inspection

\section{ABSTRACT}

\section{Keywords:}

Right to digital disconnection

Emergency decree

Protection of fundamental worker

rights

Performance of the labor inspection

A new "technological workforce" has broken into our lives, the declaration of the state of emergency ended up showing that our labor regulations were not "prepared" to face the labor problems caused by the pandemic. However, the Peruvian State, through various emergency decrees (DU) tried to alleviate the scenarios caused by the impossibility of carrying out face-to-face work. Thus, through DU 026-2020 dated March 15, 2020, remote work was established; subsequently, on November 1, 2020, DU 127-2020, brought with it the recognition of the right to digital connection; however, as it is an exceptional and temporary measure, its regulation through a DU is not enough. Therefore, this research aims to provide a scope for its regulation, which goes hand in hand with the performance of the labor inspection.

\footnotetext{
${ }^{1}$ Investigadora independiente, Abogada por la Universidad Católica Santo Toribio de Mogrovejo. Email: melissa.tavara.18@gmail.com. ORCID: https://orcid.org/0000-0002-6793-0478

${ }^{2}$ Investigador independiente, Abogado. Magíster en Derecho Empresarial por la Universidad Nacional Pedro Ruiz Gallo. Inspector del Trabajo en la Superintendencia Nacional de Fiscalización Laboral. Email: guillermo.chira@gmail.com. ORCID: https://orcid.org/0000-0003-0948-5633
} 


\section{Introducción}

El uso de las nuevas tecnologías de la información y comunicación (TIC) ha transformado nuestra forma de vida, no siendo ajeno a ello, su uso en el ámbito laboral, incrementándose aún más con la realización del trabajo remoto, el cual apareció como una especie de "salvavidas laboral" mediante el DU 026-2020 en marzo del presente año, con la finalidad de evitar la propagación del Covid-19.

Llamadas de trabajo fuera de la jornada laboral, correos electrónicos enviados a cualquier hora del día, las reuniones por Zoom, Google Meet o las diversas plataformas virtuales, los incontables mensajes por WhatsApp y las horas que pasamos sentados frente a nuestras computadoras, son algunas de las conductas que se han impuesto en nuestro "mundo laboral", evidenciándose así una "hiperconectividad" y una errada idea del empleador al considerar que su trabajador está siempre "disponible".

Por ello, si bien reconocemos la importancia de las tecnologías, pues nos permiten la prestación de servicios en cualquier lugar $y$, muchas veces de forma más rápida, su uso también ha ocasionado que se subyugue nuestro derecho al descanso, que no se logre la tan ansiada conciliación entre la vida laboral, personal y familiar, más aún con el establecimiento del trabajo remoto, al convertir nuestros hogares en nuestro centro de labores, cuesta más "desconectarnos" del trabajo.

Bajo este contexto, el Poder Ejecutivo recientemente publicó el DU 127-2020 (de fecha 01 de noviembre de 2020), estableciendo el otorgamiento de subsidios para la recuperación del empleo formal en el sector privado $y$, asimismo, instauró otras disposiciones, como el reconocimiento del derecho a la desconexión digital, evidenciando la problemática del trabajo remoto decretado mediante DU 026-2020 en marzo del año en curso.

Sin embargo, si bien el Estado peruano ha reconocido la necesidad de poner un alto a la vulneración de los derechos fundamentales que ocasiona el mal uso de las tecnologías por parte del empleador, consideramos que ello no es suficiente, toda vez que el mismo es una medida excepcional y de carácter temporal; por lo que, una vez terminada la pandemia $y$, cesando el trabajo remoto dejaría de existir el derecho a la desconexión digital.
Por tanto, si bien la iniciativa del Poder Ejecutivo es meritoria, debemos analizar la importancia de establecer una ley especial para el reconocimiento y desarrollo efectivo de este derecho, que no solo debe regularse de manera excepcional o producto de la coyuntura, puesto que, mucho antes que se declare el estado de emergencia, nuestra realidad laboral ya había cambiado. Por ejemplo, al salir de nuestros centros de labores éramos requeridos por nuestro empleador, respondíamos mensajes de Whatsapp incluso por las noches a nuestros jefes o compañeros, recibíamos correos electrónicos fuera del horario laboral, etc.

En este sentido, la regulación de este nuevo derecho no obedece solo al trabajo remoto, sino a la protección de derechos fundamentales del trabajador, a su descanso, salud y a lograr una conciliación de la vida laboral, personal y familiar, producto del mal empleo de las TIC. Asimismo, la regulación de este derecho a través de una ley especial resulta una herramienta indispensable para el desarrollo de un procedimiento inspectivo eficaz, toda vez que la vigilancia para el cumplimiento de este derecho demanda una norma especial que, de manera clara, determine las conductas vulneratorias, permitiendo una efectiva actuación de la inspección del trabajo.

Por ello, el presente artículo analizará el establecimiento del derecho a la desconexión digital en nuestro país y brindará una propuesta en busca de una correcta y permanente regulación, la cual pueda permitir, asimismo, una eficaz actuación de la inspección del trabajo.

\section{Origen y definición del derecho a la desconexión digital}

Antes de analizar el establecimiento del derecho a la desconexión digital en nuestro país, a través del DU $127-$ 2020, daremos una breve mirada al origen de este derecho y trataremos de definir el mismo.

Este derecho, que para muchos aún es un tema nuevo, tiene su origen normativo en Francia, siendo reconocido como tal el 01 de enero de 2017, a través de la Loi 10882016 conocida también como Loi Travail o Loi El Khomri. Sin embargo, su surgimiento se dio de manera paulatina, existiendo antes de su creación, algunos fallos emitidos por los Tribunales franceses $y$, ante ciertas medidas adoptadas por algunas empresas al evidenciar la problemática de la disponibilidad del trabajador fuera de su horario de trabajo debido al uso 
de las TIC (Tecnologías de la Información y Comunicación).

Como se afirma en BBC News (2014) una de esas medidas, por ejemplo, fue otorgada por la empresa alemana Volkswagen que, en diciembre de 2011, anunció que los servidores dejarían de enviar correos electrónicos 30 minutos después del final de los turnos de los empleados y que recién volverían a empezar media hora antes de que la persona volviera a trabajar. Asimismo, la empresa Mercedes Benz en el año 2014, ofreció el sistema mail on holiday, por medio del cual los correos enviados a trabajadores que se encontraban de vacaciones eran automáticamente redirigidos a otros contactos disponibles dentro de la empresa, evitando así el que lleguen a sus destinatarios durante las fechas de vacaciones (Prevención integral, 2017).

Como observamos, las primeras medidas adoptadas por las empresas buscaban la protección del trabajador a través de la prohibición del envío de correos electrónicos fuera de la jornada laboral o durante su periodo de vacaciones, la finalidad era no interrumpir los tiempos de descanso del trabajador, buscando que ni siquiera el mismo sea importunado.

En este contexto, el documento base que sirvió para establecer el derecho a la desconexión en Francia fue el informe elaborado por Bruno Mettling, director general de la empresa Orange, en dicho informe señaló como debía ser entendido el derecho a la desconexión, definiéndolo como:

(...) una corresponsabilidad del trabajador y del empleador que, depende tanto de la educación a nivel individual como de la regulación a nivel de la empresa. Este derecho y este deber a la desconexión deberían ser establecidos de manera concertada con los representantes del personal e ir acompañados con medidas de sensibilización al uso de los instrumentos digitales. (Ministerio de Empleo y Seguridad Social, 2015, p. 136)

De esta forma, en Francia se agregó un nuevo apartado, 7) en el artículo L. 2242-8 del Código de Trabajo, dentro de la sección "igualdad profesional entre las mujeres y los hombres y calidad de vida en el trabajo", estableciendo que la negociación anual sobre la igualdad profesional entre mujeres y hombres y la calidad de vida en el trabajo se centra en:

las modalidades del pleno ejercicio por el trabajador de su derecho a la desconexión y la puesta en marcha por la empresa de dispositivos de regulación de la utilización de los dispositivos digitales, a fin de asegurar el respeto del tiempo de descanso y de vacaciones, así como de su vida personal y familiar. A falta de acuerdo, el empleador, previa audiencia del comité de empresa o, en su defecto, de los delegados de personal, elaborará una política de actuación al respecto. Esta política definirá las modalidades de ejercicio del derecho a la desconexión y preverá, además, la puesta en marcha de acciones de formación y de sensibilización sobre un uso razonable de los dispositivos digitales, dirigida a los trabajadores, mandos intermedios y dirección. (Fernández, 2020, s/p.) (la negrita es nuestra)

Asimismo, España incorporó el derecho a la desconexión digital a través de la Ley Orgánica 3/2018 de Protección de Datos y Garantías de los Derechos Digitales. El artículo $88^{\circ}$ de la mencionada ley, en los siguientes términos:

1. Los trabajadores y los empleados públicos tendrán derecho a la desconexión digital a fin de garantizar, fuera del tiempo de trabajo legal o convencionalmente establecido, el respeto de su tiempo de descanso, permisos y vacaciones, así como de su intimidad personal y familiar. (la negrita es nuestra)

2. Las modalidades de ejercicio de este derecho atenderán a la naturaleza y objeto de la relación laboral, potenciarán el derecho a la conciliación de la actividad laboral y la vida personal y familiar y se sujetarán a lo establecido en la negociación colectiva o, en su defecto, a lo acordado entre la empresa y los representantes de los trabajadores. (la negrita es nuestra)

3. El empleador, previa audiencia de los representantes de los trabajadores, elaborará una política interna dirigida a trabajadores, incluidos los que ocupen puestos directivos, en la que definirán las modalidades de ejercicio del derecho a la desconexión y las acciones de formación y de sensibilización del personal sobre un uso razonable de las herramientas tecnológicas que evite el riesgo de fatiga informática. En particular, se preservará el derecho a la desconexión digital en los supuestos de realización total o parcial del trabajo a distancia, así como en el domicilio del empleado vinculado al uso con fines laborales de herramientas tecnológicas". (la negrita es nuestra) 
En ambas normativas, observamos que no existe una definición exacta sobre el derecho a la desconexión digital, se establece, más bien, su finalidad y la obligatoriedad de cumplimiento por parte del empleador. En este sentido, una definición con la cual concordamos de cómo debe ser entendido el derecho a la desconexión digital es la siguiente:

Es el derecho que tienen los trabajadores a no desarrollar actividades por fuera de la jornada de trabajo, ni a ser contactados por el empleador o sus representantes, a través de medios digitales o electrónicos; sin que su actitud negativa, pasiva y evasiva signifique desaprobación alguna en el ámbito de la relación de trabajo. (Naranjo, 2017, p. 51)

En concordancia con esta definición, podemos definir el derecho a la desconexión digital como el derecho que tiene todo trabajador de no estar disponible o sentirse obligado a cumplir órdenes de su empleador mediante algún medio tecnológico terminada su jornada laboral y; a la vez, es un deber del empleador no importunar y respetar los derechos fundamentales de los trabajadores, al descanso, a la salud y procurar la conciliación entre la vida laboral, personal y laboral.

Asimismo, es preciso mencionar que, en España la desconexión digital fuera del horario de trabajo es materia de Inspección Laboral, siendo que el artículo 7.5 de la ley de infracciones del orden social, establece como infracción grave la transgresión de las normas y límites legales o pactados en materia de jornada, trabajo nocturno, horas extraordinarias, horas complementarias, descansos, vacaciones, permisos, registro de jornada, $y$, en general, el tiempo de trabajo. (Gilarranz, 2020)

En el caso de nuestro país, contamos con el Reglamento de la Ley General de Inspección del Trabajo, aprobado por el Decreto Supremo $N^{\circ}$ 019-2006-TR, el cual contempla en su artículo 25, numeral 25.6 que constituye una infracción muy grave en materia de relaciones laborales el incumplimiento de las disposiciones relacionadas con la jornada de trabajo, refrigerio, trabajo en sobretiempo, trabajo nocturno, descanso vacacional y otros descansos, licencias, permisos y el tiempo de trabajo en general, dicha infracción posibilita el inicio del procedimiento inspectivo pero, como se analizará más adelante, al haber establecido el derecho a la desconexión digital mediante un DU, ello no permite un actuar eficaz en el desarrollo de las actuaciones inspectivas, y mucho menos, predictibilidad al momento de la imposición de sanciones, dado que las conductas que afectarían el derecho a la desconexión laboral no están delimitadas o identificadas y este vacío o deficiencia de la norma posibilitaría evadir dicha obligación por parte de los empleadores.

\section{Breve referencia a los derechos fundamentales protegidos por el derecho a la desconexión digital}

Como se observa, el derecho a la desconexión digital surgió a partir de la vulneración de derechos fundamentales de los trabajadores, a respetar su descanso y disfrute del tiempo libre; asimismo, como una obligación del trabajador de no hostigar a sus empleados fuera de la jornada laboral. En este sentido, el derecho a la desconexión englobaría la protección de ciertos derechos como: la jornada de trabajo, el derecho a la salud, el derecho al descanso y disfrute del tiempo libre; procurando lograr la tan deseada conciliación entre la vida laboral, personal y familiar. Por ello, es preciso referirnos brevemente a estos derechos.

\subsection{Derecho a la jornada de trabajo}

En nuestro país, las normas que reconocen y regulan la Jornada de Trabajo son las siguientes: el artículo 25 de la Constitución peruana; el Decreto Legislativo № 854 modificado por la Ley № 27671 (21.02.2002), el Texto Único Ordenado de la Ley de Jornada de Trabajo, Decreto Supremo № 007-2002-TR (04.07.2002) y su Reglamento el Decreto Supremo № 008-2002-TR.

Nuestra Constitución establece este derecho laboral específico en el artículo 25, el cual sostiene que:

La jornada ordinaria de trabajo es de ocho horas diarias o cuarenta y ocho horas semanales, como máximo. En caso de jornadas acumulativas o atípicas, el promedio de horas trabajadas en el período correspondiente no puede superar dicho máximo.

Los trabajadores tienen derecho a descanso semanal y anual remunerados. Su disfrute y su compensación se regulan por ley o por convenio.

Asimismo, el TC (2006) en el EXP. N.o 4635-2004-AA/TC ha establecido lo siguiente, en el caso de la vulneración de la jornada de trabajo de trabajadores mineros: 
El Tribunal Constitucional no comparte tal afirmación, según la cual el acuerdo de respetar la jornada de ocho horas, establecida en el artículo 22. del Convenio Colectivo celebrado por el demandante y el demandado para el período 2001 a 2007, es una mera "cláusula convencional declarativa". El derecho a la jornada de ocho horas diarias, reconocido y garantizado por la Constitución en su artículo 25.ำ y en los Tratados Internacionales de Derechos Humanos, no es un enunciado declarativo e inane, mera declaración, (más aún cuando integra el estándar mínimo de derechos que el Estado Peruano se ha comprometido a respetar y garantizar), sino una disposición jurídica del más alto rango y cuya fuerza jurídica vincula no sólo a los poderes públicos y a la Administración, sino también a los particulares. Cuando las partes pactan respetar dicha jornada en un convenio colectivo que, conforme al inciso 2.0 del artículo 28. de la Constitución, tiene fuerza vinculante en el ámbito de lo concertado, en modo alguno se puede considerar que tales derechos no vinculen a $s$ partes que celebraron tal convenio colectivo. (fundamento 38).

Es decir, la jornada laboral establecida en la Constitución se instaura como un límite que debe ser respetado por el empleador para acordar las horas de prestación de servicios de sus trabajadores, la cual debe ser respetada tanto en el ámbito público como privado.

Debe quedar claro que el tiempo de trabajo no es una mera condición laboral, sino que, como ha señalado el TC, es una norma del más alto rango, debido a una manifiesta influencia en el tiempo de vida del trabajador, por lo que se torna imprescindible su respeto. Es solo a través del conocimiento y respeto de la jornada de trabajo, el empleado puede programar sus actividades personales o familiares.

\subsection{Derecho al descanso y disfrute del tiempo libre}

El derecho al descanso y al disfrute del tiempo libre:

Constituyen derechos fundamentales consagrados en normas internacionales ratificados por el Perú como lo son la Declaración Universal de los Derechos Humanos (art. 24), el pacto internacional de derechos económicos, sociales y culturales (art. 7), el protocolo de San Salvador (art. 7), que forman parte del bloque de constitucionalidad con el que tiene que leerse el derecho a la jornada máxima prevista en el artículo 25 de nuestra
Constitución (Corte Suprema Casación Laboral N 3780-2014 de 06 de julio de 2016, considerando 9).

Nuestra Constitución, en el artículo 25 anteriormente referido, señala en el segundo párrafo: "los trabajadores tienen derecho al descanso semanal y anual remunerados. Su disfrute y su compensación se regulan por ley o por convenio". Asimismo, contamos con el decreto legislativo $\mathrm{N}^{\circ} 713$ sobre los descansos remunerados de los trabajadores sujetos al régimen laboral de la actividad privada.

De igual forma, respecto al descanso diario, Ramos (2007) señala:

Se debe producir entre un día y otro de trabajo, es decir, entre dos días laborables. Su finalidad no es otra que la protección de la salud del trabajador, por lo que resulta obligado establecer una pausa obligatoria de descanso entre jornada y jornadas. La cual constituye un período de tiempo que no admite ni fracción ni renuncia. Erigiéndose en barrera de contención frente al poder de dirección empresarial, por lo que el juego de la autonomía colectiva o de la individual solo admite una función de mejora de la duración legal del mismo. (p.126) (el subrayado es nuestro).

Esta definición nos recuerda la importancia de realizar una pausa obligatoria entre dos días laborables, la cual, en principio no admite renuncia; sin embargo, podemos observar en la realidad y, aún más con la realización del trabajo remoto o teletrabajo que podemos superar incluso 12 horas de estar sentados frente a la computadora cumpliendo con nuestras labores, a veces sin darnos cuenta, puesto que el estado de emergencia ha provocado de que desdibuje aún más la línea que divide el tiempo de trabajo con el de descanso.

Asimismo, Arce (2013) afirma que:

El fundamento social de la jornada de trabajo se basa en que mediante el tiempo libre el individuo se consolida como ciudadano. No se puede concebir una democracia sin personas que vuelquen sus tiempos libres en las cuestiones cívicas. Asimismo, los tiempos libres mejoran el ambiente familiar, recreacional o cultural de los trabajadores. De igual forma, la necesidad de los tiempos libres apunta a una protección de la salud del trabajador. (p.431) 
En este sentido, es necesario que todos gocemos de nuestro tiempo libre, dedicándolo a alguna actividad que nos guste, no solo es tener un derecho al descanso, sino disfrutar esas horas libres, el tiempo de ocio, entendido como actitud para afrontar el tiempo libre de forma autónoma y satisfactoria. Por tanto, implica la gestión de actividades escogidas libremente con el fin de disfrutar, descansar y sentirse realizado. (Muñoz, 2012)

Finalmente, debe quedar claro, que muchas veces, el tiempo de ocio es mal entendido, equiparándolo a algo negativo, "al no hacer nada"; por el contrario, como afirma Aristóteles el ocio parece contener en sí mismo el placer y la felicidad y la vida dichosa, porque en él llevamos a cabo actividades que son un fin en sí mismas, es decir, lo que nos ayuda a desarrollar nuestra personalidad y sentirnos felices.

\subsection{Derecho a la salud}

De igual forma, otro de los derechos protegidos por el derecho a la desconexión, es el derecho a la salud. Este se encuentra establecido en el artículo 7 de nuestra Carta Magna que señala que: "todos tienen derecho a la protección de su salud, la del medio familiar y la de la comunidad, así como el deber de contribuir a su promoción y defensa". De igual forma, el artículo $10^{\circ}$ del Protocolo Adicional a la Convención Americana sobre derechos humanos en materia de derechos económicos, sociales y culturales establece que "toda persona tiene derecho a la salud entendida esta como el disfrute del más alto nivel de bienestar físico, mental y social".

El derecho a la salud "es un derecho elemental que tienen todas las personas porque es, en realidad, equivalente al propio derecho a la vida. La salud tiene diversas dimensiones, todas fundamentales para su debida protección”. (Rubio, 2012 p.22)

En cuanto a la protección de la salud dentro del ámbito laboral, tenemos la Ley $N^{\circ} 29783$ - Ley de Seguridad y Salud en el Trabajo, la cual fue aprobada el 20 de agosto de 2011, esta normativa contiene un título preliminar junto a ciento tres artículos, además de disposiciones complementarias y finales. Si bien no se hará un análisis de toda la Ley, es preciso mencionar el principio de prevención, el cual refiere que:

El empleador garantiza, en el centro de trabajo, el establecimiento de los medios y condiciones que protejan la vida, la salud y el bienestar de los trabajadores, y de aquellos que, no teniendo vínculo laboral, prestan servicios o se encuentren dentro del centro de labores. Debe considerar factores sociales, laborales y biológicos, diferenciados en función del sexo, incorporando la dimensión de género en la evaluación y prevención de los riesgos en la salud laboral.

Asimismo, el artículo 49 de la referida ley establece las obligaciones del empleador, en el inciso a) estipula: "garantizar la seguridad y la salud de los trabajadores en el desempeño de todos los aspectos relacionados con su labor, en el centro de trabajo o con ocasión del mismo".

En este sentido, la protección de la salud dentro de una relación laboral se constituye como una obligación del trabajador, garantizando su seguridad e implementando las medidas necesarias para una debida protección.

Por tanto, el hecho de sobrecargar al trabajador con tareas asignadas durante el tiempo de descanso, produce en él un estrés que puede perjudicar su salud. Ahora más, con el uso de las TIC la situación de riesgo del trabajador en cuanto a su salud empeora, no solo por el estrés, sino también repercute en dolencias físicas, al estar muchas horas frente a la computadora afecta en general al cuerpo (padecer de constantes dolores de espalda, de cabeza e incluso ocasionar daños a la vista).

Asimismo, dentro de las enfermedades que existen debido al uso excesivo de las TIC, está el famoso síndrome de burnout, el cual se ha convertido en un trastorno muy frecuente en el mundo empresarial, este trastorno ha tomado tanta importancia que la Organización Mundial de la Salud lo ha catalogado como un riesgo laboral que se evidencia en los profesionales. (Muñoz, Rodríguez y Niebles, 2016)

Este síndrome también conocido como "síndrome del desgaste profesional o "cabeza quemada"”, está relacionado con la hiperconectividad, debido a que el sentirse obligado a responder solicitudes de su jefe o sus clientes fuera del horario convencional, contribuye del mismo modo a que el personal sienta que no puede descansar plenamente, o atender asuntos de su vida privada sin interrupciones y sin estar permanentemente atado a las necesidades de la empresa. (Fiordelmondo, 2017). 
Esta situación de sentirnos obligados a responder los requerimientos de nuestros jefes, de no sentirnos "desconectados" del trabajo, ocasionan un mayor estrés y perjudica enormemente nuestra salud, situación que a veces no advertimos o consideramos que "es normal".

\section{La conciliación de la vida personal, familiar y laboral frente a las TIC}

La conciliación de la vida personal, familiar y laboral, como del mismo nombre se puede colegir, busca una armonía en los distintos ámbitos de una persona; es decir, que pueda mantener su carrera profesional, pasar tiempo en familia, dedicarse a la educación de sus hijos (si en caso los tiene) y a desarrollar su personalidad libremente, dedicando tiempo a sí mismo, lo que no es otra cosa que el disfrute del tiempo libre a través del ocio.

En este sentido, la conciliación de la vida familiar, laboral y personal contribuye a construir una sociedad basada en la calidad de vida de las personas, primando las mismas oportunidades tanto para mujeres y los hombres, con el fin de poder desarrollarse en todos los ámbitos, como atender las responsabilidades familiares y disfrutar el tiempo tanto familiar como personal. (Fundación mujeres, 2010)

Por su lado, lo más cercano que encontramos en nuestra normativa laboral respecto a promover la conciliación de la vida personal, familiar y laboral en relación al trabajo a distancia, es el Decreto Supremo $N^{\circ}$ 009-2015-TR, que aprueba el Reglamento de la Ley $\mathrm{N}^{\circ}$ 30036, Ley que regula el teletrabajo, considerando a dicha conciliación, como un principio establecido en el inciso d) del artículo IV del Título Preliminar, señalando que "se debe promover un equilibrio entre las actividades realizadas en los ámbitos, personal, familiar y laboral de los trabajadores o servidores civiles, a través de la modalidad de teletrabajo. En tal sentido, deberá existir una adecuada correspondencia entre la carga de trabajo y la jornada de labores o servicios asignada".

Sin embargo, con el uso masivo de las nuevas tecnologías, el anhelo de lograr una armonía en estos planos de nuestra vida parece casi irreal, ello se agravó aún más con la realización de trabajo remoto, evidenciado en este estado de emergencia, lo difícil que resulta dividir los espacios cuando realizamos trabajo en casa. El tiempo de descanso parece desaparecer ante esta "laboralidad virtual", siendo que en muchos días solo nos detenemos para alimentarnos y luego seguimos inmersos en nuestras labores a través de nuestra computadora.

Asimismo, esta instauración del trabajo remoto ha deteriorado el tiempo en familia, debido a que, a través de la sobrecarga laboral digital, sumado a las clases virtuales de los hijos crea un escenario en el cual los propios niños pasan más tiempo usando los medios tecnológicos, sin contar que muchos padres se han convertido en "maestros" de sus hijos, irrumpiendo muchas veces su jornada laboral para atender las necesidades de su familia y el hogar, terminado por realizar hasta dos o más actividades al mismo tiempo.

De igual forma, las incontables reuniones vía Zoom o de cualquier otra plataforma tecnológica, han ocasionado que los trabajadores sigan conectados fuera de su jornada laboral, toda vez que la mayoría de estas reuniones son programadas en horarios supuestamente "cómodos" para que los trabajadores puedan conectarse, no usando el horario laboral para la realización de las mismas.

Muchas veces no somos conscientes del daño que puede producir el uso excesivo de las nuevas tecnologías, por tanto, es necesario poner un freno a estas situaciones y trabajar en conjunto, tanto empleador como trabajador. En este sentido, la regulación del derecho a la desconexión digital se torna necesaria debido a que nuestras normas laborales no se ajustan a la realidad, no permiten al trabajador accionar de manera específica y rápida ante esta vulneración de sus derechos, incluso para protegerlos de ellos mismos, ante la equivocada idea que al "trabajar todo el día eres más eficiente".

La regulación del derecho a la desconexión digital tiene como finalidad proteger los derechos anteriormente mencionados, siendo fundamental para que el ser humano pueda desarrollarse como tal y preservar su salud. Lamentablemente, nos hemos convertido en una especie de "esclavos tecnológicos", regresando en el tiempo de la Revolución Francesa, donde tanto costó conseguir las ocho horas de descanso y, lejos de ir reduciendo nuestra jornada laboral, las TIC han incrementado el tiempo de trabajo, más aún con la realización del trabajo remoto, a veces sin darnos cuenta o porque creemos que estamos en la obligación de estar "disponibles" en cualquier hora del día para nuestro empleador, creyendo erradamente que existe una especie de poder de dirección" supremo" al que no podemos hacer frente. 
¿Cuántas veces se ha percibido o vivido la situación de estar con algún amigo o familiar durante su "tiempo libre" y en ese momento recibir una llamada de trabajo?, ¿cuántas veces "nos han dejado de lado" para responder una llamada porque "es urgente"?, ¿cuántas veces hemos estado "compartiendo tiempo en familia y a la vez en una reunión laboral vía Zoom, silenciando la misma?

Debemos terminar con estas situaciones, sobre todo desterrar la equivocada idea de que "mientras más horas trabajamos al día, somos mejores" o, mejor dicho, "mientras más horas estemos conectados a través de las TIC por motivos laborales somos más productivos". Por el contrario, se ha demostrado que, ante el desgaste de los trabajadores por el uso excesivo de las TIC, se realiza un trabajo deficiente que puede resultar perjudicial económicamente para la empresa, pues al tener un personal que padece, por ejemplo, del síndrome de Burnout provoca que se vea mermada la calidad de la producción, las ganancias, se elevan los costos de fabricación, daña la imagen, desajusta el clima organizacional, en resumen, baja la competitividad. (Rivero, 2018).

Por tanto, sostenemos la postura de que el derecho a la desconexión digital surge ante la necesidad de paliar la problemática que ha traído consigo el uso excesivo de las nuevas TIC, que como hemos mencionado ya, se ha incrementado con la realización del trabajo remoto, pero el mismo no debe ser la causa de su regulación, como ha ocurrido en nuestro país. En este sentido, el derecho a la desconexión digital busca proteger los derechos fundamentales ya desarrollados, que si bien están preservados constitucionalmente, la normativa laboral actual no resulta suficiente y eficaz para la protección de los mismos, y a su vez, la regulación propuesta se hace imprescindible como una herramienta para que la inspección del trabajo pueda cumplir con el servicio público de velar por el cumplimiento de las normas socio laborales y de seguridad y salud en el trabajo.

\section{Escenario del establecimiento del derecho a la desconexión en el Perú y la problemática de su regulación a través del DU 127-2020.}

Como se ha mencionado en la parte introductoria de la presente investigación, el derecho a la desconexión digital en el Perú tiene su origen a raíz del trabajo remoto que apareció como una especie de "salvavidas laboral" ante la situación de emergencia sanitaria, siendo definido por la misma norma, en el artículo 16, como "aquel que se caracteriza por la prestación de servicios subordinada con la presencia física del trabajador en su domicilio o lugar de aislamiento domiciliario, utilizando cualquier medio o mecanismo que posibilite realizar las labores fuera del centro de trabajo, siempre que la naturaleza de las labores lo permita".

En este contexto, el DU 127-2020 publicado el 01 de noviembre de 2020, establece en la disposición complementaria modificatoria única, el cambio de algunos articulados del DU 026-2020 (Decreto de Urgencia que establece diversas medidas excepcionales y temporales para prevenir la propagación del Coronavirus en el territorio nacional), incorporando el derecho a la desconexión como una obligación del empleador, en el siguiente sentido:

\subsection{Son obligaciones del empleador:}

(...).

18.1.4. Respetar el derecho a la desconexión digital del trabajador, por el cual este último tiene derecho a desconectarse de los medios informáticos, de telecomunicaciones y análogos utilizados para la prestación de servicios durante los días de descanso, licencias y periodos de suspensión de la relación laboral. (la negrita y subrayado son nuestros)

18.1.5 Para el caso del sector privado, observar las disposiciones sobre jornada máxima de trabajo que resulten aplicables conforme a las normas del régimen laboral correspondiente.

El empleador no puede exigir al trabajador la realización de tareas o coordinaciones de carácter laboral durante el tiempo de desconexión digital. (la negrita es nuestra)

Tratándose de trabajadores no comprendidos en la jornada máxima de trabajo, de conformidad con la normativa vigente en la materia, el tiempo de desconexión debe ser de, al menos, doce horas continuas en un periodo de veinticuatro horas, además de los días de descanso, licencias y periodos de suspensión de la relación laboral.

18.1.6 Para el caso del sector público, la Autoridad Nacional del Servicio Civil - SERVIR podrá emitir disposiciones complementarias sobre la presente materia. 
Como podemos observar, el DU 127-2020 establece el derecho a la desconexión digital, tratando de dar una definición en el apartado 18.1.4; asimismo, indica que los trabajadores del sector privado tendrán que regirse de acuerdo con la normativa sobre la jornada máxima de trabajo. De igual forma, respecto a los trabajadores no comprendidos dentro de la jornada máxima, establece que el tiempo de desconexión debe ser de al menos 12 horas continuas.

En este sentido, el DU en cuestión es un gran paso para el establecimiento del derecho a la desconexión digital; sin embargo, no debe entenderse que su regulación se deriva de la realización del trabajo remoto, pues como sabemos, estas medidas se dan en un contexto de excepcionalidad y transitoriedad, por ello, una vez terminado el estado de emergencia y con él, el trabajo remoto, significaría que también desaparezca el derecho a la desconexión digital. Ante ello, es preciso hacernos la siguiente pregunta, ¿el derecho a la desconexión digital solo debe protegerse en la realización del trabajo remoto?

Como ha quedado claro a lo largo del presente artículo, la respuesta es negativa, este derecho a la desconexión digital no tiene su origen en la realización de trabajo remoto, sino al uso inadecuado de las nuevas TIC por parte del empleador, independientemente de la forma de prestación de servicios, pues ya con anterioridad a la declaración del estado de emergencia venían ocurriendo situaciones de abuso por parte del empleador por la exigencia de trabajo fuera de la jornada laboral, mediante el uso de las TIC; por tanto, la finalidad de este derecho es la protección del derecho a la salud, al descanso del trabajador, que este pueda conciliar su vida laboral y personal. Por tanto, no podemos limitar la protección de este derecho a un Decreto de Urgencia.

\section{Aspectos que deben ser abordados por la ley del derecho a la desconexión digital en el Perú}

Por lo expuesto, se sostiene que el derecho a la desconexión digital debe ser regulado a través de una ley especial; aunque existen opiniones contrarias, como la de Rosenbaum (2019), quien sostiene que "el contenido mínimo del derecho a la desconexión encuentra un espacio ya ocupado por los institutos clásicos que conforman el tiempo de trabajo, así como también se inserta en la finalidad protectora del derecho fundamental a la seguridad y salud en el trabajo". (p. 171)
Sin embargo, somos de una opinión distinta, atendiendo a la realidad peruana. Se necesita una ley que proteja al trabajador frente a una situación que trasgrede los derechos fundamentales ya señalados, que, si bien están reconocidos constitucionalmente, son constantemente vulnerados por esta nueva "laboralidad digital".

La ley del derecho a la desconexión digital debe establecer el ámbito de aplicación, su objeto, la definición del derecho a la desconexión digital; asimismo, identificar las manifestaciones que serían consideradas como transgresoras de los derechos fundamentales al descanso, a la salud de los trabajadores y a la conciliación de la vida personal, familiar y laboral por causa del mal empleo de las TIC; de igual forma, esta ley debe señalar la actuación de la inspección del trabajo.

En este sentido, el proyecto de ley tendrá por objeto regular el derecho a la desconexión digital, creando mecanismos que ayuden a diagnosticar, prevenir, evitar, corregir y sancionar todo tipo de conducta que afecte los derechos al descanso, disfrute del tiempo libre, y salud del trabajador producto del mal uso de las nuevas tecnologías fuera de su jornada laboral, siendo que su ámbito de aplicación, será para todas las entidades sujetas al régimen laboral de actividad pública y/o privada, con o sin fines de lucro, como son entidades, empresas, organizaciones o centros de trabajo. Asimismo, el sujeto activo será toda aquella persona que tiene la calidad de empleador o representante de este, y que al interior de la relación laboral incurre transgrediendo el derecho a la desconexión. De igual forma, el sujeto pasivo será todo aquel trabajador, que al término de su jornada de trabajo recibe las conductas que afectan su derecho a la desconexión digital. El sujeto activo tendrá como obligaciones: i) planificar y organizar las labores y actividades para evitar y prevenir cualquier tipo de riesgo que pueda afectar el derecho a la desconexión digital, ii) velar por los derechos del trabajador: al descanso, disfrute del tiempo libre y a su salud, tanto física como psíquica, manteniendo aislado toda acción que pueda representar un menoscabo de los mismo y, iii) promover un equilibrio entre las actividades realizadas en los ámbitos, personal, familiar y laboral de los trabajadores. En tal sentido, deberá existir una adecuada correspondencia entre la carga de trabajo y la jornada de labores o servicios asignada. (Távara, 2019)

La falta de desconexión digital podrá manifestarse por medio de las siguientes conductas: i) Órdenes 
impartidas por el empleador o sus representantes mediante llamadas telefónicas, correos electrónicos, aplicativos virtuales o cualquier medio digital fuera de la jornada de trabajo o ii) Programación de reuniones vía Zoom o cualquier plataforma virtual fuera de la jornada de trabajo. Asimismo, entre los principios que rigen la desconexión digital, se deben tener en cuenta: el principio de irrenunciabilidad, razonabilidad, el principio de buena fe laboral y el principio de tipicidad. En tanto que, la autoridad administrativa de trabajo, al tener conocimiento de la vulneración del derecho a la desconexión digital, deberá iniciar un procedimiento de inspección de acuerdo con la Ley General de Inspección en el Trabajo y su Reglamento. (Távara, 2019)

De igual forma, como una de las disposiciones complementarias de esta ley especial, se debe agregar un inciso al artículo $30^{\circ}$ del Texto Único Ordenado del Decreto Legislativo № 728, Ley de Productividad y Competitividad Laboral, aprobado por Decreto Supremo № 003-97-TR. En el siguiente sentido:

Artículo 30.- Son actos de hostilidad equiparables al despido los siguientes:

(...)

h) Los actos que afecten el derecho a la desconexión laboral.

Asimismo, en el último párrafo del artículo $30^{\circ}$ del Texto Único Ordenado del Decreto Legislativo № 728, Ley de Productividad y Competitividad Laboral, aprobado por Decreto Supremo № 003-97-TR, debería adicionarse el siguiente texto:

Los actos que afectan el derecho a la desconexión laboral se investigan y sancionan conforme a la ley sobre la materia.

Del mismo modo, debe modificarse el artículo $49^{\circ}$ de la Ley $N^{\circ} 29783$ - Ley de Seguridad y Salud en el Trabajo, agregando un inciso, quedando el texto de la siguiente forma:

Artículo 49. Obligaciones del empleador

El empleador tiene las siguientes obligaciones:

(...)

h) Identificar las acciones que puede afectar o representar una amenaza para el derecho a la desconexión laboral, y disponer lo necesario para la adopción de medidas de prevención por dicho riesgo.
Ante nuestra propuesta de regulación, es preciso mencionar que los países pioneros como Francia y España regulan este derecho a la desconexión digital a través de la negociación colectiva, siendo que como países que han alcanzado una importante flexibilidad laboral, su regulación mediante negociación colectiva resulta efectiva; sin embargo, la situación en nuestro país es distinta, teniendo un derecho laboral más protector del trabajador, por lo que no podríamos dejar en manos de la negociación colectiva la regulación de este derecho.

\section{La actuación de la Superintendencia Nacional de Fiscalización Laboral para garantizar el derecho a la desconexión digital}

En el marco de esta propuesta de regulación, es importante resaltar la importancia de la actuación inspectiva del trabajo, con la finalidad de que contribuya a detectar y corregir las trasgresiones del derecho a la desconexión laboral. En este sentido, haremos una breve reseña respecto a la actuación de la inspección del trabajo frente al estado de emergencia y cómo coadyuvaría en la protección del derecho a la desconexión digital.

\subsection{La Inspección del Trabajo en el estado de emergencia sanitaria.}

El sistema de inspección del trabajo peruano no es ajeno al contexto de las regulaciones dadas por el Poder Ejecutivo, a través de los Decretos Supremos $N^{\circ} 008$ 2020, $\mathrm{N}^{\circ}$ 020-2020 y $\mathrm{N}^{\circ}$ 027-2020, estableciendo diversos mecanismos de prevención y control para evitar la propagación del COVID-19, siendo una de las figuras más importantes, para los trabajadores, el establecimiento del trabajo remoto y la preferencia por los medios digitales para la tramitación de diversas actuaciones y procedimientos de índole administrativo.

Es por ello que la actuación de la Inspección del Trabajo adquiere mayor importancia debido a la necesidad de que la prestación de servicios por parte de los empleados se desarrolle cumpliendo condiciones que permitan garantizar la salud y la vida de los trabajadores, y no solo de los trabajadores de las empresas, sino los del propio cuerpo inspectivo que desarrolla la actividad de fiscalización.

Prueba de lo anteriormente señalado lo constituye la emisión del Decreto Legislativo $N^{\circ}$ 1499, el cual establece diversas medidas para garantizar y fiscalizar la protección de los derechos sociolaborales de los 
trabajadores en el marco de la emergencia sanitaria ocasionada por el COVID-19, dicha norma recoge en su tercera disposición complementaria final que durante la emergencia sanitaria, a efectos de salvaguardar la salud e integridad del personal y de los administrados, las notificaciones emitidas por la Autoridad Administrativa de Trabajo en el marco de los servicios prestados en exclusividad y el cumplimiento de obligaciones sustantivas de parte de los/as administrados/as se realizan vía correo electrónico.

Bajo ese contexto, se ha emitido un protocolo específico que establece las reglas y disposiciones para la vigilancia y exigencia del cumplimiento del ordenamiento jurídico sociolaboral y el de seguridad y salud en el trabajo dentro del marco de la Declaratoria de Emergencia Sanitaria y Nacional por las graves circunstancias que afectan las actividades laborales y económicas a consecuencia del coronavirus (COVID-19) en el territorio nacional, cuya última versión se publicó el día 11 de julio de 2020, mediante Resolución de Superintendencia $N^{\circ}$ 103-2020-SUNAFIL (Aprueban la versión 2 del Protocolo $\mathrm{N}^{\circ}$ 005-2020-SUNAFIL/ INII, denominado Protocolo sobre el ejercicio de la inspección del trabajo dentro del marco de la declaratoria de emergencia sanitaria y nacional por las graves circunstancias que afectan las actividades laborales y económicas a consecuencia del Coronavirus (COVID-19) en el territorio nacional. (Egúsquiza y Gayoso, 2020, p.111)

\subsection{La Inspección del Trabajo como servicio público}

En el contexto antes descrito y teniendo siempre presente que el Convenio 81 de la Organización Internacional del Trabajo, ratificado por el Perú mediante la Resolución Legislativa $N^{\circ} 13284$, obliga al Estado peruano a mantener un Sistema de Inspección del Trabajo encargado de velar por la protección de los derechos laborales. Frente a esta situación nos preguntamos ¿se presentan las condiciones técnicas y legales para que dicho servicio público pueda velar por el cumplimiento del novísimo derecho a la desconexión digital?

Al respecto, como ya se ha mencionado, en nuestro país, la desconexión digital encuentra su origen en el Decreto de Urgencia № 026-2020, norma que fue dada para establecer diversas medidas excepcionales y temporales que buscaban prevenir la propagación del Covid-19 en el territorio peruano; es decir, el contexto en el cual surgió a raíz de una norma que tiene como finalidad revertir situaciones extraordinarias e imprevisibles, que no depende de la "voluntad" de la misma norma, sino de datos fácticos previos a su promulgación.

Por lo tanto, ¿correspondería que la Inspección del Trabajo, que es un servicio público encargado de velar por el cumplimiento de las normas de orden sociolaboral y de seguridad y salud en el trabajo, establezca responsabilidades administrativas que procedan, orientar y asesorar técnicamente en dichas materias, vigile si los empleadores vienen cumpliendo con respetar el derecho de los trabajadores a desconectarse de los diversos medios informáticos, de telecomunicaciones $u$ análogos que normalmente utiliza para la prestación del trabajo remoto, tanto al término de la jornada diaria como durante los días de descanso, licencias y periodos de suspensión de la relación laboral?

Dicho de otro modo, la inspección del trabajo, ¿debería fiscalizar que el empleador no exija al trabajador la realización de tareas o coordinaciones de carácter laboral durante el tiempo de desconexión digital?

\subsection{Escenario actual y la dificultad de fiscalización laboral ante una posible infracción del derecho a la desconexión digital}

Una fiscalización que busca el cumplimiento del derecho a la desconexión digital como parte del trabajo remoto, resultaría a priori viable, si tomamos en cuenta que el artículo 11 de la Ley N²8806, Ley General de Inspección del Trabajo (en adelante LGIT), modificado por el Decreto Legislativo $N^{\circ} 1383$ del 04 de septiembre de 2018, establece que las actuaciones inspectivas de investigación se desarrollan mediante requerimiento de información por medio de sistemas de comunicación electrónica. En el mismo sentido la última modificación a este artículo 11 la proporcionó el Decreto Legislativo N 1499 del 10 de mayo de 2020, el cual establece que cualquiera que sea la modalidad con que se inicien las actuaciones inspectivas, estas podrán proseguirse o completarse mediante el uso de tecnologías de la información y comunicación (virtual).

Resultaría posible, desde una primera mirada, porque la fiscalización laboral, a través de los medios tecnológicos, podría recibir pruebas por parte del trabajador al cual se ha vulnerado su derecho a la desconexión, demostrando que existe una comunicación o requerimiento por parte del empleador fuera de la jornada laboral. 
Además, porque la actuación de requerimiento de información por medio de sistemas de comunicación electrónica no afecta la objetividad de una investigación donde se busque determinar el cumplimiento del derecho a la desconexión digital, como sí podría afectar en aquellas situaciones cuando la inspección de trabajo investiga un caso de actos hostiles por no asignación de labores o la desnaturalización de un contrato modal que demanda la aplicación del principio de primacía de la realidad, o el tan recurrente registro de trabajadores en planilla, entre tantas otras materias, en las cuales resulta imprescindible el desarrollo de la actuación inspectiva de visita para determinar con certeza, si se vienen cumpliendo o no las normas socio laborales o de SST.

Por ello, en el caso de una trasgresión del derecho a la desconexión digital, las actuaciones inspectivas pueden realizarse a través de requerimiento de información utilizando las TIC habilitadas para evitar el contagio del COVID-19, tales como la casilla electrónica, mensajes de texto, Ilamadas telefónicas, WhatsApp, correos electrónicos, videoconferencias, entre otras plataformas tecnológicas, o aplicativos informáticos que permitan el envío y acuse de recibo; además, del registro, grabación, impresión o notificación del requerimiento realizado y la respectiva respuesta del empleador por tales medios.

Sin embargo, toda esta accesibilidad para el desarrollo de las actuaciones inspectivas con respecto a una posible vulneración del derecho a la desconexión digital, encuentra una barrera infranqueable en los vacíos que presenta nuestra legislación interna, la primera de ellas y la más importante, tiene que ver con el Decreto Supremo N 019-2006-TR que aprueba el Reglamento de la Ley General de Inspección del Trabajo (en adelante, el Reglamento), pues no ha establecido como parte de las conductas infractoras en materia de relaciones laborales la de incumplir con las obligaciones dispuestas por el artículo 18 del Decreto de Urgencia 026-2020, modificado por el reciente Decreto de Urgencia $N^{\circ}$ 127-2020 que regula el derecho a la desconexión digital; por tanto, cualquier fiscalización al respecto resultaría infructuosa, toda vez que si bien la fiscalización laboral no persigue la sanción económica o multa, la misma resulta necesaria para exigir al empleador cese con este tipo de conductas.

\subsection{Propuesta de solución para una efectiva fiscalización respecto al derecho a la desconexión digital.}

Una alternativa de solución que haría viable no solo la fiscalización laboral, sino que se pueda velar por el cumplimiento de dicho derecho sería la aprobación de la ley propuesta para regular el derecho a la desconexión digital, toda vez que la misma describiría los sujetos, las conductas, y demás puntos a tomar en cuenta para el respeto y cumplimiento de dicho derecho, por lo que, una vez incorporada dicha infracción en el Reglamento se podría proceder a requerir su cumplimiento y a sancionar cuando corresponda.

Asimismo, al realizarse la modificación expuesta en el apartado 6 de la presente investigación, esto es, incluir en el artículo 30 de la Ley de Productividad y Competitividad Laboral, como acto hostil: Ios actos que afecten el derecho a la desconexión digital, se podría permitir una correcta y legal actuación de la Inspección del Trabajo.

Es decir, al tipificarse como acto hostil, "los actos que afecten el derecho a la desconexión digital", permitiría la aplicación del Reglamento de la Ley General de Inspección del Trabajo, respecto a conductas ya reguladas como infracciones laborales muy graves, como es el caso del inciso 25.15 que establece como infracción: "No adoptar las medidas necesarias para prevenir o cesar los actos de hostilidad, (...).

Por tanto, es necesaria la creación de una ley especial para el derecho a la desconexión digital, y disponer en la misma, las modificaciones mencionadas en el apartado 6 , siendo que todo acto que atente contra dicho derecho debe ser considerado como acto hostil y seguir el procedimiento respectivo, de esta forma, la Inspección de Trabajo podría tratar como una infracción contenida en el artículo 25.15 del Reglamento de la Ley General de Inspección del Trabajo.

Finalmente, debemos precisar que no coincidimos con las posturas que sostienen que a partir del DU 127-2020 se pueden imponer sanciones económicas por parte de la Superintendencia Nacional de Fiscalización Laboral, debido a que la Inspección del Trabajo tiene como parte de sus funciones la de establecer las responsabilidades administrativas producto de alguna infracción regulada por el Reglamento de la Ley General de Inspección del Trabajo, por lo que al no estar tipificadas las conductas que afectan el derecho a la desconexión digital por 
dicho Reglamento, en principio no se puede establecer responsabilidades o sanciones de forma análoga, además, evidenciaría una clara afectación al principio de tipicidad. Por ello, una solución sería incorporar el inciso mencionado en el artículo 30 de la LPCL para darle un tratamiento como acto hostil, y no ser incluido dentro del inciso g) de manera general; debido a que la conducta debe ser determinada como ya lo hemos expuesto a lo largo del presente artículo y, además por los derechos que pretende sean protegidos, siendo su contenido más extenso de lo señalado en el inciso g) del artículo 30 de la Ley de Productividad y Competitividad Laboral.

\section{Conclusiones}

El derecho a la desconexión digital debe ser entendido como el derecho que tienen los trabajadores a no desarrollar actividades fuera de la jornada laboral a través de medios digitales, electrónicos o análogos; sin que su actitud negativa o evasiva signifique falta alguna dentro del ámbito de la relación de trabajo; asimismo, el derecho a la desconexión digital implica la obligación del empleador a no contactar o requerir a sus trabajadores, por algún medio digital, electrónico o análogo fuera de la jornada laboral, ello con la finalidad de proteger el derecho a la salud, al descanso y disfrute del tiempo libre.

El derecho a la desconexión digital en el Perú se estableció a través del DU 127-2020, el 01 noviembre de 2020; sin embargo, al ser una medida de carácter excepcional y temporal, una vez finalizado el trabajo remoto, los trabajadores se quedarían sin la protección del derecho a la desconexión digital. Por tanto, la regulación de este derecho debe darse a través de una ley especial, para todos los trabajadores, independientemente de la forma de prestación de servicios.

En el Perú es necesaria una ley del derecho a la desconexión digital, donde se establezca el ámbito de aplicación, el objeto, los sujetos, la definición del derecho, las manifestaciones que serían consideradas como transgresoras de este derecho, entre otras.

Asimismo, dentro de la ley del derecho a la desconexión digital deben incorporarse disposiciones finales $y$ complementarias, modificando el artículo 30 de la Ley de Productividad y Competitividad Laboral, agregando un inciso h), incorporándose como acto hostil "Ios que afecten el derecho a la desconexión digital", pudiendo aplicar el respectivo procedimiento, por ejemplo, a través de una Carta de Cese de Acto Hostil o, ser el caso el pago de una indemnización por despido indirecto.

De igual forma, debe modificarse el artículo 49 de la Ley de Seguridad y Salud en el Trabajo, estableciéndose como obligación del empleador "identificar las acciones que puede afectar o representar una amenaza para el derecho a la desconexión laboral y disponer lo necesario para la adopción de medidas de prevención por dicho riesgo", salvaguardando el derecho a la salud, que también es finalidad del derecho a la desconexión digital.

La actuación de la Inspección del Trabajo es imprescindible para fiscalizar el cumplimiento del derecho a la desconexión digital, siendo que, a través de su incorporación como acto hostil, permitiría tratarlo como una infracción muy grave del empleador, contenida en el artículo 25.15 del Reglamento de la Ley General de Inspección del Trabajo, respetando así los principios de legalidad y tipicidad.

El Decreto de Urgencia 127-2020 publicado el 01 de noviembre de 2020 no es suficiente para hacer efectivo el respeto del derecho a la desconexión digital, y muchos menos habilita a los inspectores de trabajo a establecer responsabilidades o sanciones de forma análoga, además, evidenciaría una clara afectación al principio de tipicidad. Por ello, una solución sería incorporar el inciso mencionado en el artículo 30 de la LPCL para darle un tratamiento como acto hostil.

Se debe ser consciente de la necesidad de una modificación de las normas laborales, pues no se ajustan a esta nueva "laboralidad digital". Lejos de reducir la jornada de trabajo, se está cayendo en una especie de "esclavitud tecnológica", poniendo en riesgo la salud, afectando el tiempo de descanso y disfrute del tiempo libre que son vitales para el desarrollo personal y que, además, obstaculizan la conciliación entre la vida laboral, familiar y personal. 


\section{Bibliografía}

Arce, E. (2013). Derecho individual del trabajo en el Perú. Desafíos y deficiencias. Palestra.

BBC News. (11 de abril de 2014). ¿'Se pueden prohibir los correos fuera del horario de oficina? Recuperado el 11. XI. 2020 en https://www.bbc.com/mundo/noticias/2014/04/14041 1 tecnologia francia correos desconectar trabajo rg

Candamio, J. (07 de diciembre de 2018). Derecho a la desconexión digital fuera del ámbito laboral ¿qué es y por qué la nueva Ley de Protección de Datos pretende regularlo? Recuperado el 11. XI 2020 en https://www.iberley.es/revista/derecho-desconexiondigital-fuera-ambito-laboral-nueva-lopd-pretenderegularlo-116.

Egúsquiza, B. y Gayoso, G. (2020). "Regulación especial de la inspección del trabajo debido a la emergencia sanitaria por el COVID-19". Soluciones Laborales, $\mathrm{N}^{\circ}$ 152, p.p. 108-125.

Fernández, C. (02 de enero de 2020). En Francia entra en vigor el derecho a la desconexión. Recuperado el 10. $\mathrm{XI}$ 2020 en http://noticias.juridicas.com/actualidad/noticias/11540 -en-francia-entra-en-vigor-el-derecho-a-la039\%3Bdesconexion-digital039\%3B-del-trabajadorcon-la-empresa/.

Fiordelmondo, M.I. (31 de mayo de 2017). Desconexión laboral: ¿ंes necesaria su regulación? Recuperado el 11. XI. 2020. En https://www.elobservador.com.uy/nota/desconexionlaboral-es-necesaria-su-regulacion--2017531500.

Fundación Mujeres (2010). Conciliación de la vida laboral, familiar y personal. Ministerio de Igualdad editor. Recuperado el 11. XI. 2020. En https://ib.ccoo.es/59dcfc524039611a7b562ebb78c9cd 00000061.pdf.

Gilarranz, Alberto (2020). El derecho a la desconexión digital y la sanción de trabajo. Recuperado el 11. XI. 2020. En

https://www.lawyerpress.com/2020/10/09/elderecho-a-la-desconexion-digital-y-la-sancion-detrabajo/.
Ministerio del Empleo y seguridad Social (2015), "Transformación Digital y Vida Laboral: Las Propuestas del Informe Mettling". Actualidad Internacional Sociolaboral № 194, pp. 135-136. [Ubicado el 20. V 2017]. Obtenido

en http://www.mites.gob.es/ficheros/ministerio/mundo/r evista ais/194/REVISTA-194.pdf

Muñoz, D., Rodríguez, J. R. \& Niebles, W. (2016). "El autocuidado del síndrome de burnout". Una reflexión teórica: Saber, Ciencia y Libertad, Vol. 11, N² 2, Juliodiciembre, p.p. 97-103. https://dialnet.unirioja.es/descarga/articulo/5880874. pdf.

Naranjo, L. D. (2017). Vicisitudes del nuevo derecho a la desconexión digital: Un análisis desde la base del derecho laboral. Saber, Ciencia y Libertad, núm. 2, vol. 12, p.p. $49-57$.

https://dialnet.unirioja.es/servlet/articulo?codigo $=655$ 6861pp. 49-57.

Prevención integral. (31 de enero de 2017). En Francia entra en vigor el derecho a la 'desconexión digital' del trabajador con la empresa. Recuperado el 10.XI.2020 en https://www.prevencionintegral.com/actualidad/notici as/2018/09/05/en-francia-entra-en-vigor-derechodesconexion-digital-trabajador-con-empresa.

Ramos, M. I. (2007). Los Descansos Laborales, p.p. 121141. Recuperado el 11 XI. 2020 en https://app.vlex.com/\#WW/vid/316297678.

Rosenbaum, F. (2019). Manual de tiempo de trabajo. F.C.U.

Rubio, M. (2012). Para conocer la Constitución de 1993. PUCP.

Távara Romero, M. (2019). El uso de las nuevas TIC y el derecho a la desconexión laboral: un límite al poder de dirección (Tesis de pregrado, Universidad Católica Santo Toribio de Mogrovejo, Chiclayo, Perú). Recuperado de http://tesis.usat.edu.pe/handle/20.500.12423/1950

Transformación digital y vida laboral: las propuestas del Informe Mettling. Actualidad Internacional Sociolaboral № $194 . \quad$ En http://www.mites.gob.es/ficheros/ministerio/mundo/r evista_ais/194/135.pdf. 
IUS Vol. 9. $N^{\circ} 2$ (2020): 73-87

\section{Legislación y jurisprudencia}

Poder Ejecutivo. (15 de marzo de 2020). Decreto de Urgencia $N^{\circ}$ 026-2020. Decreto de Urgencia que establece diversas medidas excepcionales y temporales para prevenir la propagación del Coronavirus (COVID19) en el territorio nacional. En El Peruano: https://cdn.www.gob.pe/uploads/document/file/5664 47/DU026-20201864948-1.pdf.

Poder Ejecutivo. (01 de noviembre de 2020). Decreto de Urgencia $N^{\circ}$ 127-2020. Decreto de Urgencia que establece el otorgamiento de subsidios para la recuperación del empleo formal en el sector privado y establece otras disposiciones. En El Peruano: https://busquedas.elperuano.pe/normaslegales/decret o-de-urgencia-que-establece-el-otorgamiento-desubsidi-decreto-de-urgencia-n-127-2020-1899077-1/.

Poder Ejecutivo. (28 de octubre de 2006). Decreto Supremo N ${ }^{\circ}$ 019-2006-TR. Aprueba el Reglamento de la Ley General de Inspección del Trabajo. En el Sistema Peruano de Información Jurídica: http://spijlibre.minjus.gob.pe/normativa libre/main.as p Tribunal Constitucional $(2006,04)$. STC. Exp. N 46352004-AA/TC.

https://www.tc.gob.pe/jurisprudencia/2006/046352004-AA.pdf. 